\title{
Motrivivancia
}

Revista de Educação Física, Esporte e Lazer

LaboMídia

\section{Formação profissional e mundo do trabalho: uma análise sobre a não atuação dos bacharéis em Educação Física}

\section{RESUMO}

Esta investigação teve como objetivo identificar e analisar as justificativas que levam os/as bacharéis em Educação Física a não atuarem na área de formação inicial. A pesquisa adotou a interlocução com referenciais pautados no materialismo histórico-dialético. Foi realizada em uma universidade de grande porte, localizada no interior do estado de São Paulo. Todos/as os/as formados/as do curso de bacharelado em Educação Física, no período de 2015-2018 foram convidados, por e-mail, a responder um questionário no Google Forms com questões abertas e fechadas, sendo que 56 contribuíram com a investigação. Os resultados apontaram que, pouco mais da metade dos/as participantes estão atuando na área (64,30\%). Dos/as que não estão atuando, as principais justificativas centram-se nas precárias condições de trabalho, bem como na ausência de vagas e/ou oportunidades. Por fim, dos/as bacharéis, parcela expressiva não prosseguiu nos estudos $(53,60 \%)$, contrariando os princípios para uma atuação profissional pautada em conhecimentos científicos.

PALAVRAS-CHAVE: Educação física;

Formação profissional; Mundo do trabalho;

Egressos/as; Bacharelado

\section{Laysson Henrique Ferreira de Souza}

Bacharel em Educação Física

Universidade do Oeste Paulista, Departamento de Educação Física, Presidente Prudente, Brasil laysson11@hotmail.com

http://orcid.org/0000-0003-1329-2287

Pedro Henrique Gibim Pires

Bacharel em Educação Física

Universidade do Oeste Paulista, Departamento de Educação Física, Presidente Prudente, Brasil pedrogibim123@hotmail.com

http://orcid.org/0000-0002-9818-3794

Marcos Vinicius Francisco

Pós-doutor em Educação

Universidade Estadual de Maringá, Departamento de Ciências do Movimento Humano/Programa de

Pós-graduação em Educação, Ivaiporã/Maringá, Brasil

mvfrancisco@uem.br (1) http://orcid.org/0000-0002-5410-2374

Thaís Godoi de Souza

Doutoranda em Educação

Universidade Estadual de Maringá, Departamento de Ciências do Movimento Humano, Ivaiporã, Brasil

tgsouza2@uem.br (1) http://orcid.org/0000-0002-8447-5454 


\title{
Professional training and labor of world: an analysis of the lack of performance of bachelor's degree in Physical Education
}

\begin{abstract}
This investigation aimed to identify and analyze the justifications that lead bachelors in Physical Education to not work in the area of initial training. The research adopted interlocution with references based on historical-dialectical materialism. It was carried out at a large university, located in the interior of the state of São Paulo, Brazil. All graduates of the Bachelor's Degree in Physical Education, in the 2015-2018 period, were invited, by email, to answer a questionnaire on Google Forms with open and closed questions, 56 of whom contributed to the investigation. The results pointed that just over half of the participants are working in the area (64.30\%). Of those who aren't working, the main justifications focus on the precarious working conditions, as well as the absence of vacancies and/or opportunities. Finally, of the bachelors, an expressive portion didn't continue in their studies $(53.60 \%)$, contradicting the principles for a professional performance based on scientific knowledge.
\end{abstract}

KEYWORDS: Physical education; Professional qualification; Labor of world; Graduates; Bachelor's degree

\section{La formación profesional y el mundo del trabajo: un análisis de la ausencia de atuacción de los licenciados en Educación Física}

\section{RESUMEN}

Esta investigación tuvo como objetivo identificar y analizar las justificaciones que llevan a los licenciados en Educación Física a no trabajar en el área de formación inicial. La investigación adoptó la interlocución con referencias basadas en el materialismo histórico-dialéctico. Se llevó a cabo en una gran universidad, ubicada en el interior del estado de São Paulo, Brasil. Todos los egresados de la Licenciatura en Educación Física, en el período 2015-2018, fueron invitados, por correo electrónico, a responder un cuestionario en Google Forms con preguntas abiertas y cerradas, 56 de los cuales contribuyeron a la investigación. Los resultados mostraron que más de la mitad de los participantes están trabajando como licenciados en Educación Física (64,30\%). De los que no están trabajando, las principales justificaciones se centran en las precarias condiciones laborales, así como en la ausencia de vacantes y oportunidades. Finalmente, de los bachilleres, una porción expresiva no continuó sus estudios $(53,60 \%)$, contradiciendo los principios para un desempeño profesional basado en el conocimiento científico.

PALABRAS-CLAVE: Educación física; Formación profesional; Mundo del trabajo; Graduados; Grado de bachiller 


\section{INTRODUÇÃO}

Apesar do curso de bacharelado em Educação Física ter uma grande procura e expressivo número de estudantes concluintes, questiona-se, neste artigo, quais as justificativas que levam os/as bacharéis a não atuarem na área de formação inicial? Esta problemática investigativa, dialeticamente, perpassará o texto em tela, seja na fundamentação teórica, quanto na análise dos dados empíricos.

Mediante tal questionamento, elegeu-se como objetivo geral, identificar e analisar as justificativas que levam os/as bacharéis em Educação Física a não exercerem a área de formação inicial. Assumiram-se, ainda, como objetivos específicos: averiguar em quais funções os/as recém-formados/as atuam e sintetizar os principais entraves para a inserção na área.

As relações contraditórias, historicamente situadas e estabelecidas entre sociedade e Educação Física impactam na formação inicial da área, na atualidade, por meio dos cursos de licenciatura e bacharelado. Integra tal processo a tríade capital-trabalho-educação (CRUZ; 2009; WELTER; RIBAS; SOUZA, 2018). Para Cruz (2009, p. 115), há que se levar em consideração a centralidade do trabalho na formação do ser social, que se apresenta estruturado "pelo modo e pelas relações de trabalho, próprios do sistema do capital".

Taffarel, Lacks e Santos Júnior (2006), Cruz (2009) e Nozaki (2015) ressaltam que a formação em Educação Física vem sendo influenciada pelo contexto das políticas de reformas imperialistas. Os cursos de Graduação da área, embora sempre estivessem ligados aos ditames do mercado, na atualidade estão se adequando aos discursos neoliberais que enfatizam a predominância de competências e habilidades nos processos formativos. Para os/as autores/as isso se configura como uma estratégia do capital para manter sua hegemonia. Dessa forma, há constantes disputas em torno das diretrizes curriculares para os cursos de Graduação. Tais disputas se deram "entre setores conservadores/corporativistas e setores progressistas/revolucionários pela direção ou condução teórico-político da área, convergidas nas temáticas da formação profissional e na regulamentação da própria profissão" (NOZAKI, 2015, p. 189).

De acordo com Pupio (2017) os debates na área sobre formação e atuação profissional, nos anos de 1980, giravam em torno da expansão das práticas corporais, atividade física e saúde e precarização do trabalho docente. Em meio a essas discussões alguns profissionais defendiam e idealizavam o campo não escolar como uma nova possibilidade promissora de lucros. O campo não escolar era compreendido como o universo das atividades físicas. 
As disputas pela formação em Educação Física foram nitidamente explicitadas em junho de 1987, com a Resolução do Conselho Federal de Educação (CFE) nº 03/1987 que, pela primeira vez, abriu a possibilidade para uma fragmentação na área, culminando com a criação do bacharelado em Educação Física (BRASIL, 1987). Anteriormente a essa Resolução, a formação existente na área era assegurada somente pelo curso de licenciatura.

Reconhece-se que as adequações às demandas do capital são coetâneas ao processo educacional em qualquer época, todavia se faz necessário analisar os seus desdobramentos no mundo do trabalho, a exemplo da reorganização do capital nas décadas de 1990 e 2000, as quais impactaram decisivamente à área de Educação Física. A educação, tanto básica quanto superior passou a ser balizada por quatro postulados fundamentais: competências, empreendedorismo, meritocracia e empregabilidade. Portanto, a formação em cursos de Graduação se voltou à formação de um sujeito polivalente, flexível e empreendedor (MACIEL et al., 2011).

Predominaram os interesses sobre a formação do profissional de Educação Física materializados por meio dos órgãos conselheiros da profissão, tais como o Conselho Federal de Educação Física e Conselhos Regionais de Educação Física - CONFEF/CREFs. O sistema CONFEF/CREFs teve papel decisivo no processo histórico dos debates que balizaram à aprovação das Diretrizes Curriculares Nacionais em Educação Física (DCNEF), preconizadas pela Resolução do Conselho Nacional de Educação/Câmara de Educação Superior (CNE/CES) nº. 7, de 31 de março de 2004, publicada no Diário Oficial da União, em 5 de abril de 2004, alterada pela Resolução CNE/CES no 7, de 4 de outubro de 2007, publicada no Diário Oficial da União em 5 de outubro de $2007^{1}$, ao dicotomizar o campo de atuação profissional por meio da divisão do curso em licenciatura e bacharelado (SILVA; FRIZZO, 2011; NOZAKI, 2015; WELTER; RIBAS; SOUZA, 2018). Dias (2011) denomina os órgãos conselheiros da profissão de grupo privatista, enquanto Nozaki (2004) os classifica como corporativistas.

No bojo dessa polaridade, é oportuno reconhecer que a dicotomização da área se manifestou devido à divisão social e técnica do trabalho. Destarte, há que se ponderar que a fragmentação não permite à compreensão de que os processos de construção do conhecimento fazem parte de uma totalidade, a qual não se atinge "pela soma das partes, ou pretensa "invenção" da interdisciplinaridade, mas, sobretudo pela compreensão que o conhecimento é construído pelas sucessivas mediações que são estabelecidas" (CRUZ, 2009, p. 117).

\footnotetext{
${ }^{1}$ Há uma nova resolução para os cursos de graduação em Educação Física, publicada em 18 de dezembro de 2018, a qual vem sendo alvo de críticas já que não houve uma consulta aos profissionais da área. Resolução CNE/CES $n^{\circ}$ $06 / 2018$.
} 
[...] tal dualidade, qual seja licenciatura e bacharelado não corresponde à formação qualificada para outro projeto de sociedade, mas sim para a manutenção do atual modelo de organização social que se encontra em uma crise estrutural. Esta pretensa dualidade é apenas na aparência, uma vez que os trabalhadores em formação, não têm na essência formação diferenciada. Se analisarmos os currículos veremos disciplinas iguais, ou currículos sendo "regulados" para diferenciar a formação entre licenciatura e bacharelado a partir da carga horária ou da mudança de nome da disciplina. Os conteúdos sobre os quais ambas as formações tratam são os mesmos, o que vai mudar é a intencionalidade pedagógica. A definição para os campos de atuação entre formais e não formais desconsidera a docência como a base em qualquer local de intervenção profissional (CRUZ, 2009, p. 118).

Há que se ponderar que, embora a atual Resolução n 6, de 18 de dezembro de 2018, tenha instituído as Diretrizes Curriculares Nacionais dos Cursos de Graduação em Educação Física, com uma nova roupagem, manteve a mesma lógica, ou seja, a dicotomização do processo de formação, corroborando com as análises realizadas anteriormente. Tais Diretrizes enfatizam que, mediante as exigências requeridas dos/as egressos/as, diante do futuro exercício profissional, "a formação do graduado em Educação Física terá ingresso único, destinado tanto ao bacharelado quanto à licenciatura, e desdobrar-se-á em duas etapas”. Ou seja, os/as estudantes, após a Etapa Comum, terão que optar pelos conhecimentos específicos da licenciatura ou do bacharelado (BRASIL, 2018, p. 1).

Diante do exposto, na perspectiva do método do materialismo histórico-dialético (MHD), ao assumir a prática social como ponto de partida e de chegada (SAVIANI, 2012), na expectativa de compreender os seus nexos e relações, os quais incidem diretamente na atuação dos profissionais da Educação Física, enfatizou-se o olhar para os/as bacharéis, foco analítico deste artigo.

O/A bacharel em Educação Física, no discurso governamental, é aquele/a que realiza sua intervenção "profissional em treinamento esportivo, orientação de atividades físicas, preparação física, recreação, lazer, cultura em atividades físicas, avaliação física, postural e funcional, gestão relacionada com a área de Educação Física”, dentre outras relacionadas às práticas desportivas, das atividades físicas e recreativas (BRASIL, 2018, p. 5).

No que tange ao contexto das academias, maior segmento que gera expectativas de atuação profissional dos/as futuros/as bacharéis, Mendes e Azevedo (2014) apontam que as mesmas oferecem um baixo valor pela hora/aula, e questionam o argumento daqueles/as que dizem que o/a profissional terá a possibilidade de conseguir alunos/as como personal trainer, algo que pode demorar a acontecer. No que tange às extensas jornadas de trabalho, em alguns casos, há professores/as que trabalham mais de 80 horas semanais, a fim de complementarem suas rendas. Esse quadro é agravado pelas poucas horas de sono, diversos problemas de saúde e muitos/as que 
trabalham sem carteira de trabalho assinada (MENDES; AZEVEDO, 2014; SALLES; FARIAS; NASCIMENTO, 2015).

[...] o quadro do mercado de trabalho na área de academias de atividades físicas, no atinente ao discurso dos Educadores Físicos (EFs), onde identificamos sua satisfação pessoal com o trabalho simultaneamente a queixas referentes às suas condições de trabalho, e o recorrente uso da expressão "correria" em referência ao volume de trabalho a que se submetem, trabalhando em vários locais, nem sempre com o devido contrato trabalhista legal, devido à desvalorização a que são submetidos (MENDES; AZEVEDO, 2014, p. 600).

Salles, Farias e Nascimento (2015) ponderam que as grandes barreiras identificadas pelos/as recém-formados/as, no que diz respeito à inserção profissional, são a falta de experiência e as baixas remunerações oferecidas pelos postos de trabalho. Com relação à remuneração, ela é desmotivadora e geradora de insatisfação no trabalho do/a profissional de Educação Física (FURTADO; SANTIAGO, 2015; SALLES; FARIAS; NASCIMENTO, 2015).

Reverberam com essas constatações, as análises de Furtado e Santiago (2015), para quem o grande obstáculo para se prosseguir na carreira de professor/a de Educação Física é a baixa remuneração. "Estes trabalhadores se sentem cada vez mais desmotivados a darem prosseguimento à carreira de professor de Educação Física neste espaço. A nosso ver, a precarização e desvalorização do trabalho são decisivas para esta tendência” (FURTADO; SANTIAGO, 2015, p. $327)$.

\section{Metodologia}

Por meio das dimensões quali-quantitativas, este estudo se encontra ancorado no diálogo com as produções ligadas ao método do MHD. Nessa perspectiva "[...] há que se considerar a dialética entre quantidade e qualidade e, sobretudo saltos qualitativos, na transição de quantidade para qualidade" (FRANCISCO, 2013). Tal perspectiva foi inicialmente proposta por Marx (2006) e Marx e Engels (1974), sendo todo fenômeno abordado para além do imediatismo aparente, surgindo à necessidade de se analisar a realidade em sua totalidade, diante de suas contradições e de seu movimento histórico. A contradição é um motor temporal, ou seja, é inerente à história humana, ou seja, a toda matéria, isto é, a tudo que existe (MARX; ENGELS 1974; VIEIRA PINTO, 1979; MARX, 2006).

De acordo com Paulo Netto (2011, p.25), o papel do/a pesquisador/a na perspectiva do MHD deve ser essencialmente ativo, a fim de apreender o fenômeno investigado, ou seja, ser “[...] capaz de mobilizar um máximo de conhecimentos, criticá-los, revisá-los e deve ser dotado de criatividade e imaginação". 
[...] os instrumentos e também as técnicas de pesquisa são os mais variados, desde a análise documental até as formas mais diversas possíveis de observação, recolha dos dados, quantificação etc. Esses instrumentos e técnicas são os meios de que se vale o pesquisador para "apoderar-se da matéria", mas não devem ser identificados com o método: instrumentos e técnicas similares podem servir (e de fato servem) em escala variada, a concepções metodológicas diferentes (NETTO, 2011, p.26).

Tais ponderações se aplicam aos critérios de seleção dos/as participantes e ao instrumento de coleta de dados, que em um primeiro momento poderiam ser associados às pesquisas de natureza quantitativa. Porém, nesse caso, há que se explorar outros elementos para além dos aparentemente dados via respostas dos/as participantes.

\section{Local e participantes}

A pesquisa foi realizada em uma universidade de grande porte, em município com população estimada em 227.072 habitantes, localizado no interior do estado de São Paulo (IBGE, 2019). A instituição escolhida é a maior universidade privada do oeste do estado de São Paulo, considerada a maior formadora de bacharéis em Educação Física. Em levantamento, preliminar, junto à Coordenação de curso da referida instituição, constatou-se que a universidade em tela titulou nos anos de 2015, 2016, 2017 e 2018, respectivamente, 51, 63, 124 e 52 estudantes, totalizando 290 concluintes na modalidade de bacharelado.

Cálculo do tamanho de uma amostra²:

$$
n=\frac{N \cdot Z^{2} \cdot p \cdot(1-p)}{(\mathrm{N}-1) \cdot \mathrm{e}^{2}+\mathrm{Z}^{2} \cdot \mathrm{p} \cdot(1-\mathrm{p})}
$$

Onde:

$\mathbf{n}=$ O tamanho da amostra que queremos calcular.

$\mathbf{N}=$ Tamanho do universo.

$\mathbf{Z}=$ É o desvio do valor médio que se aceita para alcançar o nível de confiança desejado. Em função do nível de confiança que se buscou, adotou-se um valor determinado que é dado pela forma da distribuição de Gauss. Os valores mais frequentes são:

Nível de confiança $90 \% \rightarrow Z=1.645$.

\footnotetext{
${ }^{2}$ Disponível em: https://pt.surveymonkey.com/mp/sample-size-calculator.
} 


$$
\begin{gathered}
n=\frac{290(1.645)^{2}(0,5)(0,5)}{289(0,05)^{2}+(1,645)^{2}(0,5)^{2}}=\frac{196,1868}{0,7225+0,6765}=141 \\
n=\frac{290(1.645)^{2}(0,5)(0,5)}{289(0,05)^{2}+(1,645)^{2}(0,5)^{2}}=\frac{196,1868}{0,7225+0,6765}=141
\end{gathered}
$$

Nível de confiança $-90 \%$

Margem de erro - $10 \%$

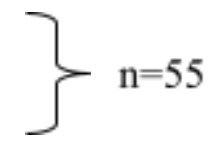

\section{Instrumento de pesquisa}

A pesquisa de campo foi realizada por meio do envio de e-mail, com convite para que os/as participantes, ou seja, todos/as os/as egressos/as em Educação Física, do curso de bacharelado, nos anos de 2015 a 2018, respondessem a um questionário com questões abertas e fechadas. $\mathrm{O}$ questionário foi disponibilizado por meio do Google Forms. Em linhas gerais, versou-se saber: a) o ano de conclusão do curso na área do bacharelado; b) qual o movimento de formação incorporado após o término do curso, ou seja, se continuaram os estudos em nível de outra Graduação, pós lato sensu ou stricto sensu; c) os cursos de formação e eventos que os/as egressos/as participaram após o término do bacharelado em Educação Física; d) em quais áreas estão atuando; e) as justificativas para estarem ou não atuando na área de formação; f) expectativas futuras na profíssão ou para além dela.

O instrumento foi disponibilizado em um endereço eletrônico durante um período de 60 dias. Vale apontar que, no endereço eletrônico também estava disponível o Termo de Consentimento Livre Esclarecido (TCLE), de acordo com os preceitos do Comitê de Ética em Pesquisa.

\section{Análise e discussão dos dados}

Ao analisar o sexo dos/as participante da pesquisa, verificou-se que 60,07\% (34) eram do sexo masculino, e 39,03\% (22) do sexo feminino. No que tange à idade dos/as participantes (Gráfico 01), o/a mais novo/a possuía 21 anos e o/a mais velho/a 46 anos de idade. Ou seja, tais dados evidenciam que o público investigado pode ser considerado como relativamente jovem. 
Gráfico 01 - Idade dos/as participantes da pesquisa

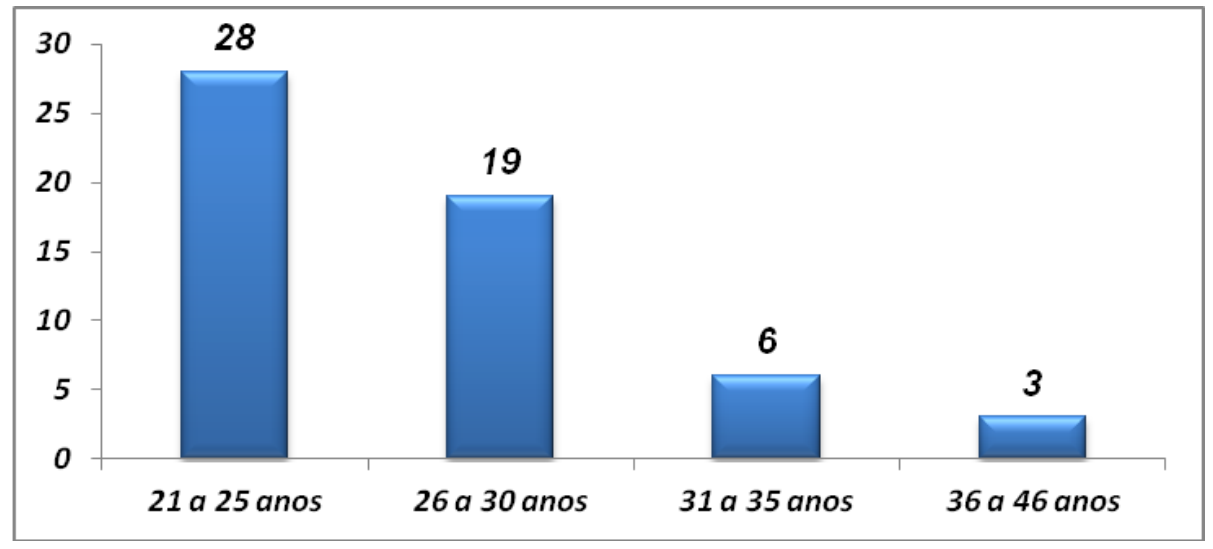

Fonte: Pesquisa de campo, 2018-2019.

Com relação ao ano de conclusão do curso de bacharelado em Educação Física, oito (08) concluíram em 2015, nove (09) em 2016, vinte e quatro (24) em 2017 e quinze (15) em 2018. Mais da metade dos/as participantes ainda não prosseguiram nos estudos, ou seja, 53,60\% (30). Esse quantitativo chama a atenção, já que o aperfeiçoamento e a formação continuada são ingredientes necessários para uma atuação profissional mais consistente, além de assegurar o contato com os avanços gerados pela produção do conhecimento na área. Dos/as que prosseguiram nos estudos, 28,60\% (16) estão realizando e/ou concluíram cursos de Especialização (pós lato sensu); 17,29\% (10) é o quantitativo dos/as que se matricularam em outros cursos de Graduação e 1,8\% (01) está cursando a pós sctricto sensu em nível de Mestrado.

Uma das contradições do capital em relação à formação educacional, em tempos de neoliberalismo, diz respeito ao novo perfil que vem sendo formado nos cursos de Educação Física, já que se exige "[...] um trabalhador que tenha um conhecimento mínimo, diferente da época taylorista, nesse sentido, o capital vive seu impasse de que os sistemas educativos acompanhem essa evolução, apenas no sentido de transmitir o conhecimento técnico e não de transformar" (WELTER; RIBAS; SOUZA, 2018, p. 137). Essa lógica os/as afeta sobremaneira, pari passu, parcela expressiva não se apropria da dimensão da pesquisa, bem como da importância do conhecimento científico e filosófico, na formação inicial, levando-os/as a uma atuação frágil, muitas vezes, pautada no senso comum.

Dados de uma pesquisa recente, desenvolvida por Triani, Magalhães Júnior e Novikoff (2017), confirmam que a maioria dos/as estudantes do curso de Educação Física, participantes do seu estudo, não conseguiram atribuir um sentido para a formação docente, mesmo diante da certeza 
de que ter conhecimentos é necessário para ser um/a profissional qualificado/a. Acrescenta-se, apenas metade acredita na sua formação.

Welter, Ribas e Souza (2018, p. 137) complementam, as relações entre trabalho e educação conduzem a uma interpretação do impacto das políticas educacionais na Educação Física e a sua função como mediadora dessa relação. "Com as crises do capitalismo, dentre elas o neoliberalismo, surgiu a necessidade de uma nova forma de exploração e alienação do ser humano para garantir a continuidade do sistema, consequentemente um novo perfil de trabalhador". Como salientado, anteriormente, tais alterações incidem na educação e nos cursos de formação inicial.

Os dados, acima apresentados, podem ser complementados com o gráfico 02, ainda na perspectiva de avaliar a continuidade dos estudos. Chamou atenção o fato de que 20 egressos/as $(35,7 \%)$, após o término da formação inicial, não participaram de nenhum curso e/ou palestras.

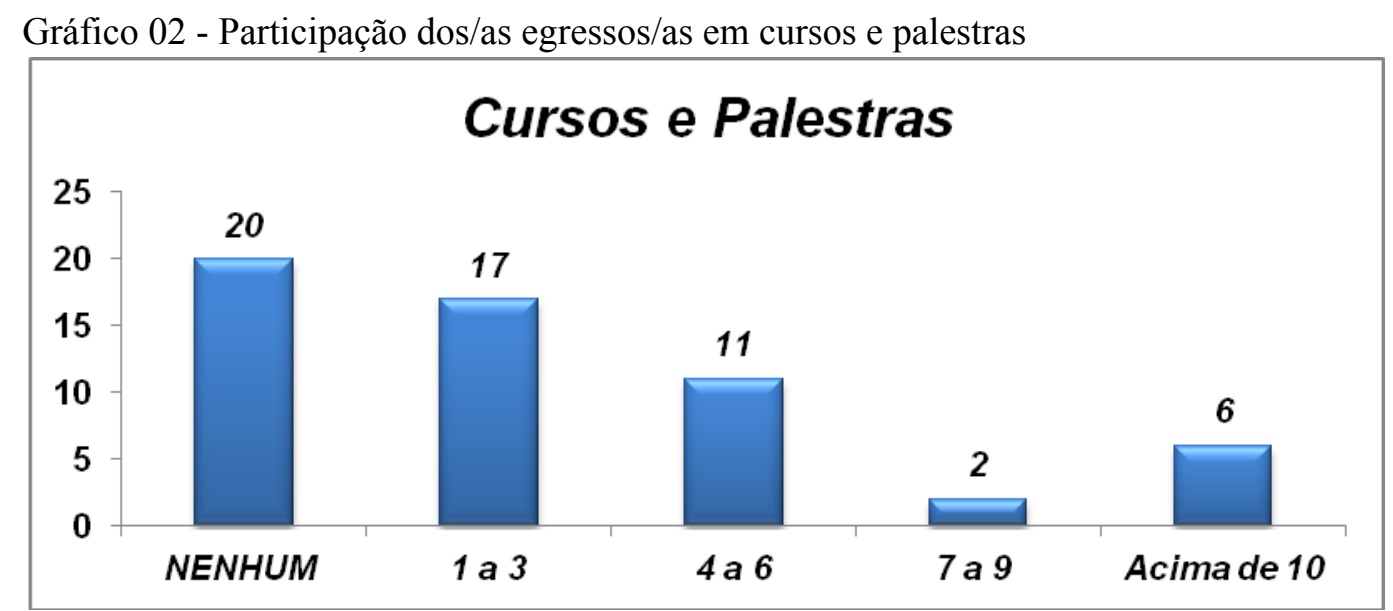

Fonte: Pesquisa de campo, 2018-2019.

Outro dado intrigante, apresentado no Gráfico 03, é que dos/as participantes da pesquisa, 25 egressos/as (44,6\%) não participaram de nenhum evento após a conclusão do curso. Poucos são os/as que adquirem o hábito constante da participação em eventos. A participação em eventos científicos é algo que deve ser cultivado desde a formação inicial, pois estes se constituem como espaços ímpares para o diálogo com outros/as pesquisadores/as da área, além de poderem socializar suas atividades profissionais. Paixão (2017) afirma que o/a profissional ao se colocar diante de uma situação de elevada e variada exigência de competência específica, demandará conhecimento das necessidades e expectativas dos/as alunos/as, que se encontram sob sua orientação/mediação. 
Gráfico 03- Egressos/as e a participação em eventos científicos

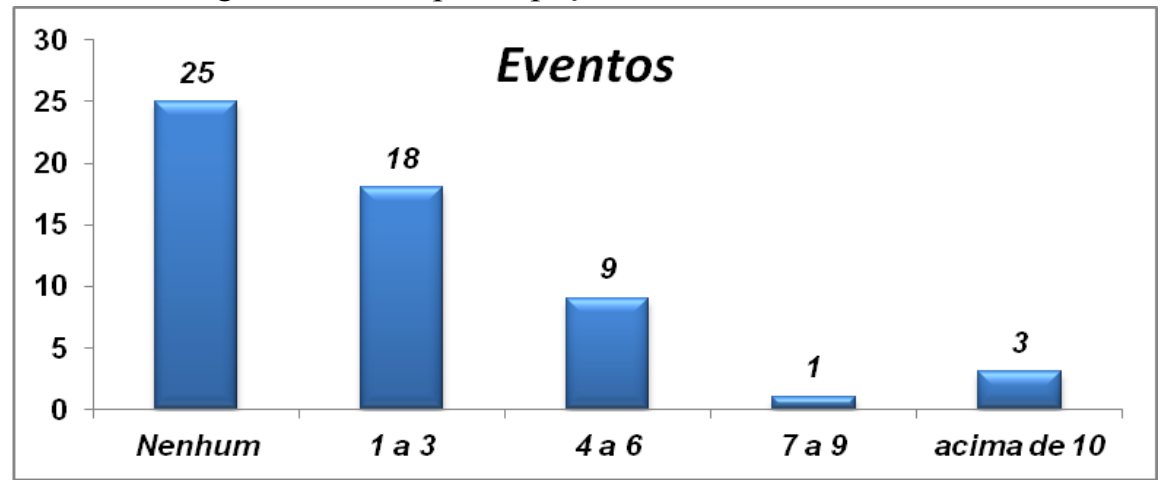

Fonte: Pesquisa de campo, 2018-2019.

Em relação à atuação profissional, embora a maioria esteja atuando na área de formação 64,30\% (36), sejam como bacharéis em academias, personal trainer, técnicos/as desportivos/as, ginástica laboral, biomecânica e nutrição, chama atenção o fato de que na maioria dos casos as relações trabalhistas são informais. Além disso, o quantitativo que não conseguiu e/ou não teve a pretensão de ingressar na área foi de 35,70\% (20). Estes/as atuam nas áreas de administração de empresas, serviço público, vendas, licenciatura, comércio ou estão desempregados.

Sem os direitos trabalhistas, intensifica-se o processo de precarização do trabalho na área de Educação Física, em especial nos espaços de atuação informal, inclusive, com a conivência do sistema CONFEF/CREFs. Nesta toada, “[...] os bacharéis são jogados no mercado de trabalho de forma precária e subcontratada" (WELTER; RIBAS; SOUZA, 2018, p. 138). "Há apenas o movimento de ampliação da retirada da mais-valia deste trabalhador, posto que, tanto do lado do assalariamento como do lado da contratação terceirizada, a empresa ganha, seja pela extração direta da mais-valia, seja pela desobrigação dos encargos contratuais" (NOZAKI, 2015, p. 192).

Nozaki $(2004,2015)$ complementa, o que lhes resta é se ocupar de várias atividades profissionais, a fim de garantir a mínima subsistência, acrescido da incerteza de que se terão seus empregos futuramente, já que o contingente de reserva de mão de obra é grande, vide os números identificados nesta investigação $(35,70 \%)$.

Para Jonas et al. (2011), em alguns casos, em um primeiro momento ocorre uma decepção com a profissão, ao fazer com que muitos/as profissionais abandonem a carreira ou assumam certo descompromisso com o processo de ensino e aprendizagem. E uma das principais dificuldades, no primeiro ano de ano de atuação profissional, é a baixa remuneração e junto com ela ganha relevo à falta de experiência e as dificuldades de colocação no mercado. Há também a falta de conhecimentos específicos que atrapalham a área de atuação, quais sejam os métodos de treinamento, fisiologia/biomecânica, postura profissional e saúde do idoso. 
De qualquer maneira, “a política neoliberal desresponsabiliza o Estado e culpabiliza o sujeito [...]. O indivíduo é responsável pelo seu sucesso ou fracasso. Se o sujeito trabalha num determinado mercado precário, ou se este está sem emprego, a culpa não recai sobre o capitalismo", apenas no/a trabalhador/a (WELTER; RIBAS; SOUZA, 2018, p. 139). Complementam os autores, a pobreza e o desemprego são ingredientes necessários para a concretização do sistema, já que se prioriza a diminuição de gastos e a alta lucratividade, independentemente de suas consequências sociais.

\section{CONCLUSÃO}

Os resultados por meio da aplicação de questionários aos/as egressos/as do curso de bacharelado em Educação Física, de uma universidade privada de grande porte do estado de São Paulo, apontaram que pouco mais da metade dos/as profissionais estão atuando na área (64,3\%), sendo que destes/as a maioria encontra-se em postos de trabalho informais. Com a conivência do sistema CONFEF/CREFs, sem direitos trabalhistas, se intensifica o processo de precarização do trabalho na área, em especial nos espaços de atuação informal.

Dos/as que não estão atuando na área (35,70\%), as principais justificativas se assentaram na baixa remuneração recebida, bem como na ausência de vagas e/ou oportunidades. Esse número expressivo revela o que se denomina de contingente de reserva de mão de obra, profissionais que ocupam outras funções, muitas vezes sem a exigência de ensino superior ou que estão desempregados/as esperando uma colocação no mercado, a fím de se garantir a mínima subsistência. Todo esse cenário está assegurado pela lógica neoliberal, a qual responsabiliza tais indivíduos pelo fracasso ou sucesso profissional, o que coaduna com as distintas formas de exploração e alienação que promovem a manutenção do status quo.

Há que se destacar, ainda, que dos/as bacharéis, parcela expressiva não prosseguiu nos estudos $(53,60 \%)$, até o presente momento, ao explicitar uma das contradições do capital, já que se defende a necessidade de uma boa atuação profissional. Parcela expressiva dos/as estudantes, nos cursos de formação inicial, não se apropria da dimensão da pesquisa, bem como da relevância dos conhecimentos científicos e filosóficos, levando-os/as a uma atuação frágil, muitas vezes, pautada no senso comum.

Além dos principais obstáculos para a atuação dos/as bacharéis em Educação Física apresentados pela pesquisa de campo, a reorganização do mundo do trabalho, atrelados aos interesses de grupos privados na área e a elaboração das mais recentes Diretrizes Curriculares para os cursos de Graduação contribuíram, sobremaneira, para a precarização da referida área. 


\section{REFERÊNCIAS}

BRASIL. Resolução nº 3, de 16 de junho de 1987. Fixa os mínimos de conteúdos e duração a serem observados nos cursos de graduação em Educação Física (Bacharelado e/ ou Licenciatura Plena). Diário Oficial da República Federativa do Brasil: seção 1, Poder Executivo, Brasília, DF, CFE, p. 9635-9636, 22 jun. 1987.

BRASIL. Resolução N 7, de 31 de março de 2004. Institui as Diretrizes Curriculares Nacionais para os cursos de graduação em Educação Física, em nível superior de graduação plena. Brasília: Conselho Nacional de educação. Câmara de Educação Superior. 2004. Disponível em: http://portal.mec.gov.br/cne/arquivos/pdf/ces0704edfisica.pdf. Acesso em 21 jun. 2019.

BRASIL. Conselho Nacional de Educação. Resolução CNE/CES n ${ }^{\circ} 6$ de 18 de dezembro de 2018. Institui Diretrizes Curriculares Nacionais dos Cursos de Graduação em Educação Física e dá outras providências. Diário Oficial da União, Brasília, DF, ed. 243, p. 48, 19 dez. 2018b. Seção 1. Disponível em: https://www.in.gov.br/materia/-/asset_publisher/Kujrw0TZC2Mb/content/id/55877795. Acesso em: 30 jan. de 2019.

CRUZ, Amália Catharina Santos. O embate de projetos na formação de professores de educação física: além da dualidade licenciatura - bacharelado. 2009. 151f. Dissertação (Mestrado em Educação). Centro de Ciências da Educação, Universidade Federal de Santa Catarina, Florianópolis, 2009.

DIAS, Fernanda Braga Magalhães. A fragmentação da formação de professores de Educação Física: minimização da formação dos à ordem do capital. 2011. 293f. Dissertação (Mestrado em Educação). Centro de Ciências da Educação, Universidade Federal de Santa Catarina, 2011.

FRANCISCO, Marcos Vinicius. A construção social da personalidade de adolescentes expostos ao bullying escolar e aos processos de "resiliência em-si”": uma análise histórico-cultural. 2013. 266f. Tese (Doutorado em Educação), Universidade Estadual Paulista, Presidente Prudente, 2013.

FURTADO, Roberto Pereira; SANTIAGO, Lorena Paes. Educação Física e trabalho: considerações a respeito da inserção profissional de egressos da FEF-UFG. Revista Brasileira Educação Física e Esporte, São Paulo, v.29, n.2, p. 325-36, abr.jun. 2015. Disponível em: http://www.scielo.br/scielo.php?script=sci arttext\&pid=S1807-55092015000200325\&lng=en\&nrm=iso. Acesso em: 25 Mar. 2021.

IBGE. Cidades: Panorama do município de Presidente Prudente. 2019. Disponível em: https://cidades.ibge.gov.br/brasil/sp/presidente-prudente/panorama. Acesso em 08 ago. 2019.

JONAS, Elaine Cristina; REDONDO, Francisco Cirnanda Fernandes Spim; NEVES, Nilson Alves das; FERNANDES, Rosemeire Gomes; SILVA, Sheila Aparecida Pereira dos Santos. Estágios na formação profissional e dificuldades percebidas por profissionais de educação física em seu primeiro ano de atuação. Revista Cocar, Belém, v. 5, n. 10, p. 95-107, jul./dez. 2011. Disponível em: https://periodicos.uepa.br/index.php/cocar/article/view/201 Acesso em: 15 fev. 2021.

MACIEL, Thiago Barreto; BELLEI, Rafael Loures dos Reis; COIMBRA, Tatiane Carneiro; SOUZA, Carlos Eduardo de; LOPES, Mônica Jardim. O reordenamento do mundo do trabalho e a Educação Física. IN: DIAS JÚNIOR, Elson Moura; LIMA, Thiago Firmino. (Orgs.). MNCR: 10 anos na luta pela regulamentação do trabalho. Feira de Santana: Editora UEFS, 2011, p.19-51.

MARX, Karl. Trabalho assalariado e capital \& Salário, preço e lucro. São Paulo: Expressão Popular, 2006.

MARX, Karl; ENGELS, Friedrich. A ideologia alemã. 11. ed. São Paulo: Martins Fontes, 1974. 
MENDES, Alessandra Dias; AZEVEDO, Paulo Henrique. O trabalho e a saúde do educador físico em academias: uma contradição no cerne da profissão. Revista Brasileira Educação Física e Esporte, São Paulo, v. 28, n. 4, p. 599-615, out./dez. 2014. Disponível em: https://www.scielo.br/scielo.php?pid=S1807-55092014000400599\&script=sci abstract\&tlng=pt Acesso em: 16 mar. 2020.

NOZAKI, Hajime Takeuchi. Educação Física no mundo do trabalho: mediações da regulamentação da profissão. 2004. 383f. Tese (Doutorado em Educação), Faculdade de Educação, Universidade Federal Fluminense, Niterói, 2004.

NOZAKI, Hajime Takeuchi. Trabalho e educação na atualidade: mediações com a educação física brasileira. Educação, Santa Maria, v. 40, n. 1, p. 183-200, jan./abr. 2015. Disponível em: https://periodicos.ufsm.br/reveducacao/article/view/13244 Acesso: 17 mar. 2021

PAIXÃO, Jairo Antônio. Dificuldades enfrentadas por professores de educação física em academias de ginástica e em escolas de educação básica no início da carreira. Pensar a Prática, Goiânia, v. 20, n. 3, p. 552-564, jul./set. 2017. Disponível em: https://pesquisa.bvsalud.org/portal/resource/pt/biblio-1046638 Acesso em: 25 mar. 2021.

PAULO NETTO, José. Introdução ao estudo do método de Marx. São Paulo: Expressão Popular, 2011.

PUPIO, Bárbara Cristina. Cadeia produtiva da indústria da cultura corporal em academias de ginástica: em busca dos nexos e determinações da tese da divisão da formação como decorrência da reestruturação produtiva. 2017. 232f. Tese (Doutorado em Educação), Universidade Federal da Bahia, Salvador, 2017.

SALLES, William das Neves; FARIAS, Gelcemar Oliveira; NASCIMENTO, Juarez Vieira do. Inserção profissional e formação continuada de egressos de cursos de graduação em Educação Física. Revista Brasileira Educação Física e Esporte, São Paulo, v. 29, n. 3, p.475-486, 2015. Disponível em:

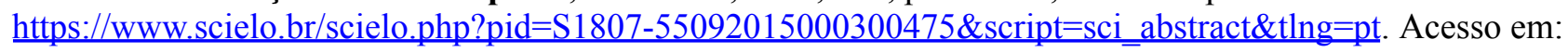
25 mar. 2021.

SAVIANI, Dermeval. Escola e democracia. 42. ed. Campinas: Autores Associados, 2012.

SILVA, Guilherme Gil da; FRIZZO, Giovanni Felipe Ernst. Crítica à regulamentação da profissão e à produção científica defensora do sistema CONFEF/CREFs. Motrivivência, Florianópolis, v. 23, n. 36, p. 149-168, jun. 2011. Disponível em: https://periodicos.ufsc.br/index.php/motrivivencia/article/view/2175-8042.2011v23n36p149. Acesso em: 20 mar. 2021.

TAFFAREL, Celi Zulke; LACKS. Solange; SANTOS JUNIOR, Cláudio de Lira. Formação de professores de educação física: estratégia e táticas. Motrivivência, Florianópolis, v. 18, n. 26, p. 89-111, jun. 2006. Disponível em: https://antigo.periodicos.ufsc.br/index.php/motrivivencia/article/view/681. Acesso: 23 mar. 2021.

TRIANI, Felipe da Silva; MAGALHÃES JÚNIOR, Carlos Alberto de Oliveira; NOVIKOFF, Cristina. As representações sociais de estudantes de educação física sobre a formação de professores. Movimento, Porto Alegre, v. 23, n. 2, p. 575-585, abr./jun. 2017. Disponível em:

https://seer.ufrgs.br/Movimento/article/view/68898. Acesso em: 25 mar. 2021.

VIEIRA PINTO, Álvaro. Ciência e existência: problemas filosóficos da pesquisa científica. 2. ed. Rio de Janeiro: Paz e Terra, 1979.

WELTER, Janaíne; RIBAS, João Francisco Magno; SOUZA, Maristela da Silva. O tripé: trabalho, capital e educação no contexto das políticas educacionais para a educação física. Revista Kinesis, Santa Maria, v. 36, 
n.1, p. 130-142, jan./abr. 2018. Disponível em: https://periodicos.ufsm.br/kinesis/article/view/26332. Acesso em: 25 mar. 2021.

\section{NOTAS DE AUTOR}

\section{AGRADECIMENTOS}

Agradecemos aos/às participantes desta pesquisa, sem eles/elas os dados aqui apresentados não seriam passíveis de serem socializados.

FINANCIAMENTO - Não se aplica.

\section{APROVAÇÃO DE COMITÊ DE ÉTICA EM PESQUISA}

Aprovado pelo Comitê de Ética em Pesquisa da Universidade do Oeste Paulista, número CAAE: 90746318.0.0000.5515, aprovado em 20 de junho de 2018.

CONFLITO DE INTERESSES - Não há conflitos de interesses entre os autores.

\section{LICENÇA DE USO}

Os autores cedem à Motrivivência - ISSN 2175-8042 os direitos exclusivos de primeira publicação, com o trabalho simultaneamente licenciado sob a Licença Creative Commons Attribution Non-Comercial ShareAlike (CC BY-NC SA) 4.0 International. Esta licença permite que terceiros remixem, adaptem e criem a partir do trabalho publicado, desde que para fins não comerciais, atribuindo o devido crédito de autoria e publicação inicial neste periódico desde que adotem a mesma licença, compartilhar igual. Os autores têm autorização para assumir contratos adicionais separadamente, para distribuição não exclusiva da versão do trabalho publicada neste periódico (ex.: publicar em repositório institucional, em site pessoal, publicar uma tradução, ou como capítulo de livro), com reconhecimento de autoria e publicação inicial neste periódico, desde que para fins não comerciais e compartilhar com a mesma licença.

\section{PUBLISHER}

Universidade Federal de Santa Catarina. Programa de Pós-Graduação em Educação Física. LaboMídia - Laboratório e Observatório da Mídia Esportiva. Publicado no Portal de Periódicos UFSC. As ideias expressadas neste artigo são de responsabilidade de seus autores, não representando, necessariamente, a opinião dos editores ou da universidade.

\section{EDITORES}

Mauricio Roberto da Silva, Giovani De Lorenzi Pires, Rogério Santos Pereira.

\section{EDITOR DE SEÇÃO}

Bianca Poffo.

\section{REVISÃO DO MANUSCRITO E METADADOS}

João Caetano Prates Rocha; Keli Barreto.

\section{HISTÓRICO}

Recebido em: 26 de março de 2021.

Aprovado em: 28 de maio de 2021. 